\title{
CORRELATION OF NECK CIRCUMFERENCE AND HEAD CIRCUMFERENCE IN DIFFERENT CRANIOFACIAL SKELETAL PATTERNS
}

\author{
Suchitra S. Prabhu1, Ramakrishna Avadhani², Rohan Mascarenhas ${ }^{3}$
}

${ }^{1}$ Associate Professor, Department of Anatomy, Century International Institute of Dental Sciences and Research Centre, Poinachi, Kerala, India.

2Professor and HOD, Department of Anatomy, Yenepoya Medical College, Mangalore, Karnataka, India.

3Professor, Department of Orthodontics and Dentofacial Orthopaedics, Yenepoya Dental College, Mangalore, Karnataka, India.

\section{BACKGROUND} ABSTRACT

The craniofacial skeletal patterns of individuals vary because of differences in anatomical features, which may be influenced by environmental or geographical or genetic factors. Body measurement data are useful in identification of individuals in medico-legal cases, medical diagnosis and also in anthropological studies.

The aim of this study was to determine the correlation between the Head Circumference (HC) and Neck Circumference (NC) in craniofacial skeletal patterns.

\section{MATERIALS AND METHODS}

The cross-sectional study of three hundred and forty seven subjects were classified in different craniofacial skeletal pattern (Vertical, Horizontal and Average) using standardised FMA, Y-axis, Growth axis, LAFH, Sn-Go-Gn and Jarabak ratio. Head and neck circumferences were measured with the help of a tape. Data was tabulated and statistical analysis (unpaired ' $t$ ' test) was carried out to find if there is any statistical significance between craniofacial patterns, head circumference and neck circumference. The correlation co-efficient was determined using Karl Pearson's formula.

\section{RESULTS}

The regression equation developed for NC using HC of Vertical, Horizontal and Average group is $-23.189+0.026 * \mathrm{HC},-27.64+$ $1.111 * \mathrm{HC}$ and $-29.304+1.153 * \mathrm{HC}$, respectively. In the present study when all groups were compared, HC was highly correlated with $\mathrm{NC}$ in all groups. It was apparent from the results that the three craniofacial skeletal patterns are significantly different from each other.

\section{CONCLUSION}

These observations can be of use while designing certain anthropometric tools or equipment and also may help in documentation of people in certain fields like Forensic Sciences as well as cosmetic and reconstructive surgery.

\section{KEY WORDS}

Head Circumference, Neck Circumference, Regression, Craniofacial Skeletal Patterns.

HOW TO CITE THIS ARTICLE: Prabhu SS, Avadhani R, Mascarenhas R. Correlation of neck circumference and head circumference in different craniofacial skeletal patterns. J. Evolution Med. Dent. Sci. 2018;7(44):4746-4748, DOI: 10.14260/jemds/2018/1059

\section{BACKGROUND}

Craniofacial skeletal pattern of individuals vary because of differences in anatomical features, which may be influenced by environmental or geographical or genetic factors. Body measurement data are useful in identification of individuals in medico-legal cases, medical diagnosis and also in anthropological studies. To date, many studies on craniofacial skeletal patterns are conducted in the field of orthodontics for treatment planning. But there is no sufficient literature available with regard to correlation between Head Circumference (HC) and Neck Circumference (NC) with different craniofacial pattern. These measurements, i.e. HC and $\mathrm{NC}$ are shown to be relevant for certain clinical diagnosis.[1-3]

'Financial or Other Competing Interest': None.

Submission 29-11-2017, Peer Review 30-07-2018,

Acceptance 06-08-2018, Published 29-10-2018.

Corresponding Author:

Suchitra S. Prabhu,

Associate Professor, Department of Anatomy,

Century International Institute of Dental Sciences and

Research Centre, Poinachi, Kasaragod-671541, Kerala, India.

E-mail: suchithra21@gmail.com

DOI: 10.14260/jemds/2018/1059

\section{(c) $(i) \ominus$}

Borges et al opine that changes in NC is correlated with snoring, which may accelerate metabolic risk.[4] As proposed by Nguyen et al, HC dimension may play an important role in certain neurodevelopmental conditions. ${ }^{[5]}$ It is also significantly associated with height and weight in children and young adults.[6] According to Ben-Noun and Laor, changes in NC are positively correlated with changes in risk for cardiovascular disease.[7]

The observation and findings of the current study may establish the correlation between Head circumference and Neck circumference in craniofacial skeletal patterns. These are useful in orthodontic surgeries, anthropometric studies, cosmetology, reconstructive surgery and forensic sciences.

\section{MATERIALS AND METHODS}

A cross-sectional study was conducted among eligible population of South Indians. Four hundred South Indians, in the age group of $18-24$, reporting to the Department of Orthodontics and Dentofacial Orthopaedics of Yenepoya University were selected for this study. Subjects suffering from malnutrition and with a history of surgery were excluded from this study. The purpose of this study was conveyed and 
consent was obtained from all subjects. This study was approved by Ethical Committee of the University.

Subjects who fulfilled all the inclusion criteria were selected and prepared for further study. From the eligible population size of 400 , finally sample size was screened to 347 by systematic random sampling. These 347 subjects were considered as total sample, out of which 121 belonged to Vertical group, 105 to Horizontal and 121 to Average group.

Digital lateral cephalograms of all 347 samples were taken using standardised cephalometric technique. The lateral cephalograms were then traced with the help of Dolphin imaging system (Software was used to analyse the cephalograms). The subjects were divided into three different groups, i.e. Vertical, Horizontal and Average using standardised FMA, Y-axis, Growth axis, LAFH, Sn-Go-Gn and Jarabak ratio values as mentioned in (Table No. 1). In order to include a subject under a particular group, at least four of the following six criteria should be met.

\begin{tabular}{|c|c|c|c|}
\hline Parameters & Average & Vertical & Horizontal \\
\hline FMA & $18^{\circ}-22^{\circ}$ & $>22^{\circ}$ & $<18^{\circ}$ \\
\hline Y-axis & $58^{\circ}-61^{\circ}$ & $>61^{\circ}$ & $<58^{\circ}$ \\
\hline Growth axis & $88^{\circ}-92^{\circ}$ & $<88^{\circ}$ & $>92^{\circ}$ \\
\hline LAFH & $65-70 \mathrm{~mm}$ & $>70 \mathrm{~mm}$ & $<65 \mathrm{~mm}$ \\
\hline Sn-Go-Gn & $28^{\circ}-32^{\circ}$ & $>32^{\circ}$ & $<28^{\circ}$ \\
\hline Jarabak ratio & $62-65$ & $<62$ & $>65$ \\
\hline \multicolumn{4}{|c|}{ Table 1. Cephalometric Parameters to Categorise the } \\
Craniofacial Skeletal Groups \\
\hline
\end{tabular}

To determine the combined tracing, localisation and measuring error, twenty-five randomly selected cephalograms were retraced fifteen days after first evaluation. No significant difference $(p>0.05)$ was found between the first and second measurement.

Head and Neck Measurements were taken for all the 347 Subjects who were randomly Selected-

1. Head Circumference: The tape was wrapped around the Glabella, superior orbital margins with superior margins of the external acoustic meatus and Inion and back to the point above the glabella.

2. Neck: It was taken at a point just below the thyroid cartilage of larynx and perpendicular to the long axis of the neck.

\section{Statistical Analysis}

Microsoft Excel (Microsoft Corp, Redmond, USA) was used to compile the data. Means and standard deviations of the measurements of all 347. Three craniofacial skeletal groups were evaluated using SPSS 17.0 version. The correlation and linear regression analysis was done. The significance value was set on $\mathrm{p}<0.05$. The correlation between cephalic and body measurements were studied on three craniofacial skeletal groups (Vertical, Horizontal and Average). The correlation coefficient was determined using Karl Pearson's formula.

\section{RESULTS}

There is a derivation of regression equation for Neck circumference estimation along with multiplication factor using Head circumference for craniofacial skeletal patterns with their respective Standard Error Estimate and Correlation coefficient (r). In Vertical, Horizontal and Average group the Head circumference showed a moderate positive correlation with Neck circumference i.e. $0.527,0.715$ and 0.645 respectively. In Horizontal group, the Head circumference showed a high correlation with Neck circumference.

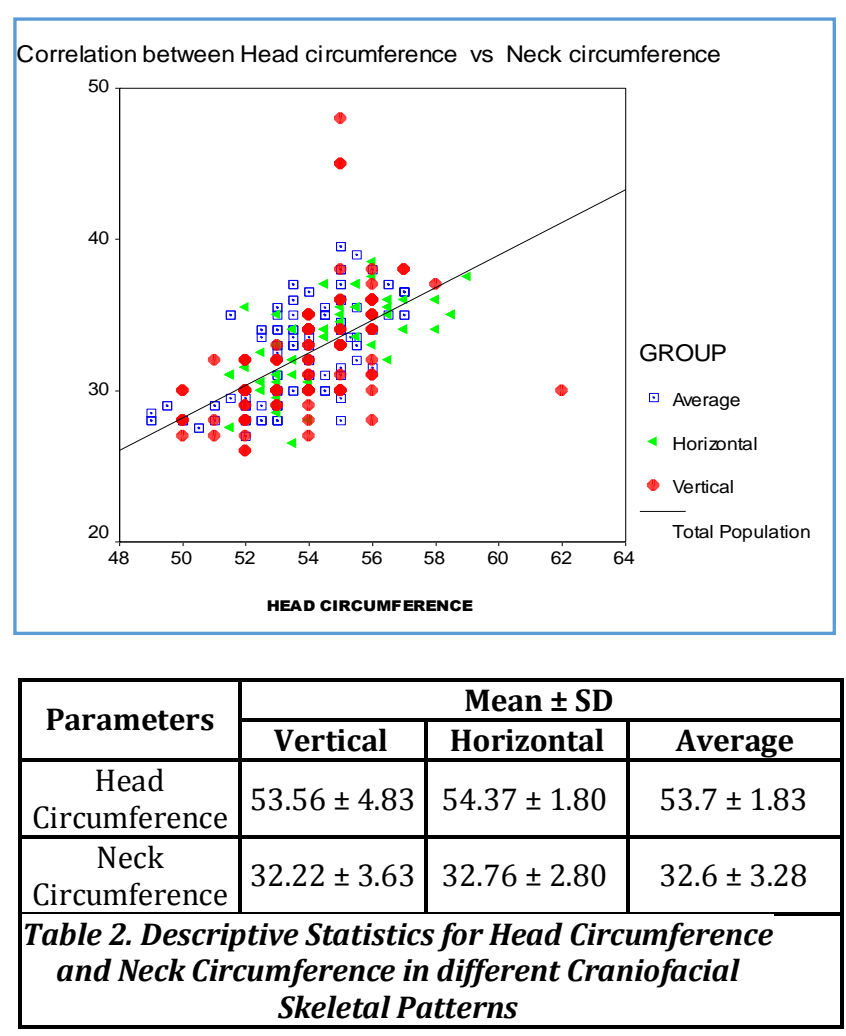

Table no. 2, Statistical analyses with derivation of regression equation (Model summary).

\begin{tabular}{|c|c|c|c|c|}
\hline Group $^{\mathbf{a}}$ & $\mathbf{R}$ & $\mathbf{R}$ Square & $\begin{array}{c}\text { Adjusted R } \\
\text { Square }\end{array}$ & $\begin{array}{c}\text { Std. Error of } \\
\text { the Estimate }\end{array}$ \\
\hline Vertical & $.527^{\mathrm{a}}$ & .278 & .272 & 3.10 \\
\hline Horizontal & $.715^{\mathrm{a}}$ & .511 & .507 & 1.96 \\
\hline Average & $.645^{\mathrm{a}}$ & .416 & .411 & 2.51 \\
\hline
\end{tabular}

a. Predictors (constant) Head Circumference

\begin{tabular}{|c|c|c|c|c|c|c|}
\hline \multirow{2}{*}{\multicolumn{2}{|c|}{ 蓄 }} & \multicolumn{2}{|c|}{ 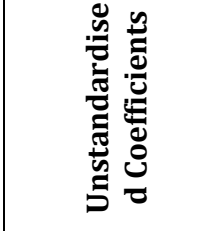 } & \multirow{2}{*}{ 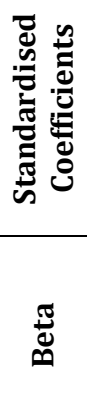 } & \multirow[t]{2}{*}{+} & \multirow[t]{2}{*}{ is } \\
\hline & & $\infty$ & 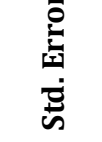 & & & \\
\hline Vertical & $\begin{array}{c}\text { Head } \\
\text { circumference } \\
\text { (Constant) }\end{array}$ & $\begin{array}{c}-23.189 \\
1.026 \\
\end{array}$ & $\begin{array}{l}8.181 \\
.152\end{array}$ & .527 & $\begin{array}{c}-2.834 \\
6.770\end{array}$ & $* * *$ \\
\hline $\begin{array}{c}\text { Hori- } \\
\text { zontal }\end{array}$ & $\begin{array}{c}\text { Head } \\
\text { circumference } \\
\text { (Constant) }\end{array}$ & $\begin{array}{c}-27.640 \\
1.111\end{array}$ & $\begin{array}{l}5.820 \\
.107\end{array}$ & .715 & $\begin{array}{l}-4.749 \\
10.384\end{array}$ & $* * *$ \\
\hline Average & $\begin{array}{c}\text { Head } \\
\text { circumference } \\
\text { (Constant) }\end{array}$ & $\begin{array}{c}-29.304 \\
1.153\end{array}$ & $\begin{array}{l}6.723 \\
.125\end{array}$ & .645 & $\begin{array}{r}-4.359 \\
9.214\end{array}$ & $* * *$ \\
\hline \multicolumn{7}{|c|}{$\begin{array}{c}\text { Table 3. Statistical Analyses with Derivation of Regression } \\
\text { Equation (Coefficients }{ }^{a} \text { ) }\end{array}$} \\
\hline
\end{tabular}


Vertical: $\quad \mathrm{NC}=-23.189+1.026 * \mathrm{HC}$

Horizontal: $\quad \mathrm{NC}=-27.64+1.111 * \mathrm{HC}$

Average: $\quad \mathrm{NC}=-29.304+1.153^{*} \mathrm{HC}$

*** - very highly significant $(\mathrm{p}<0.001)$.

\section{DISCUSSION}

Excessive adipose tissue deposition in different regions of the body may have considerable cardiometabolic implications, though they are necessary for dietary energy.[1] They are reasonably responsible for changes in $\mathrm{HC}$ and $\mathrm{NC}$ in an individual. Head circumference measurement is one of the most essential parameter in the early diagnosis of certain neurological disorders. ${ }^{[8]}$ Neck circumference is considered as a fitness key for estimating physical status of an individual. It is considered as one of the simple screening method for detecting obesity in patients.[1,7] It is also shown to be positively correlated with insulin resistance in metabolic syndrome positively. ${ }^{[2,4]}$ In the present study, maximum HC was shown by Horizontal group (54.37 \pm 1.80 ) and minimum HC was observed in Vertical group (53.56 \pm 4.83 ). However, a study by Karmegam et al demonstrated slightly lesser measurements in Malay, Chinese and Indian people.[9]

Among all the three craniofacial skeletal pattern groups, in the present study HC showed positive correlation with NC. Additionally, among all groups, Horizontal group showed good correlation (0.715) with HC. Thus, Horizontal group was showing the maximum $\mathrm{HC}$ when compared with other groups. This can be explained by the fact that circumference is a characteristic transverse growth that correlates highly in Horizontal group.

\section{CONCLUSION}

The study mainly revealed that the three craniofacial skeletal patterns were significantly different from each other. It also demonstrated that whenever HC increased, $\mathrm{NC}$ also increased in all groups. Data obtained from the present study may help in deriving a regression equation for calculating NC using HC. This can be used in reconstruction of head shape and size of a person with the help of NC. Further, using larger samples of subjects from different ethnic groups, it may establish a better correlation. The result of correlation may help us in establishing different population norms. It can also help in predicting future changes that might occur in the craniofacial complex.

\section{REFERENCES}

[1] Cho NH, Oh TJ, Kim KM, et al. Neck circumference and incidence of diabetes mellitus over 10 years in the Korean Genome and Epidemiology Study (KoGES). Scientific Reports 2015;5:18565.

[2] Preis SR, Massaro JM, Hoffmann U, et al. Neck circumference as a novel measure of cardiometabolic risk: the Framingham Heart study. J Clin Endocrinol Metab 2010;95(8):3701-10.

[3] Stabe C, Vasques AC, Lima MM, et al. Neck circumference as a simple tool for identifying the metabolic syndrome and insulin resistance: results from the Brazilian Metabolic Syndrome Study. Clin Endocrinol (Oxf) 2013;78(6):874-81.

[4] Borges PT, Filho ESF, Araujo TME, et al. Correlation of cephalometric and anthropometric measures with obstructive sleep apnea severity. Int Arch Otorhinolaryngol 2013;17(3):321-8.

[5] Nguyen AKD, Simard-Meilleur AA, Berthiaume C, et al. Head circumference in Canadian male adults: Development of a normalized chart. Int J Morphol 2012;30(4):1474-80.

[6] Geraedts EJ, van Dommelen P, Caliebe J, et al. Association between head circumference and body size. Horm Res Paediatr 2011;75(3):213-9.

[7] Ben-Noun LL, Laor A. Relationship between changes in neck circumference and cardiovascular risk factors. Experimental \& Clinical Cardiology 2006;11(1):14-20.

[8] Karabiber H, Durmaz Y, Yakinci C, et al. Head circumference measurement of urban children aged between 6 and 12 in Malatya, Turkey. Brain Dev 2001;23(8):801-4.

[9] Karmegam K, Sapuan SM, Ismail MY, et al. Anthropometric study among adults of different ethnicity in Malaysia. International Journal of the Physical Sciences 2011;6(4)777-88. 